\title{
Pengenalan Tulisan Pada Iklan Pinggir Jalan yang Melengkung Menggunakan Shape Context
}

\author{
Endang Setyati, Departemen Informatika, Institut Sains dan Teknologi Terpadu Surabaya, \\ Raymond Sugiarto, Departemen Informatika, Institut Sains dan Teknologi Terpadu Surabaya.
}

\begin{abstract}
Abstrak- Membaca sebuah tulisan yang sama di bidang melengkung berbeda dengan di bidang datar, karena tulisan pada bidang melengkung bergantung pada permukaan bidang lengkungnya. Pada saat ini, banyak sekali tulisan pada iklan pinggir jalan yang ditempel pada bidang melengkung di sepanjang jalan. Tulisan yang digunakan berupa huruf dan angka, dengan berbagai macam background, bentuk dan warna yang diambil di pinggir jalan dengan menggunakan Farey Shape Context. Fitur Farey ini bergantung pada DSS (Digital Straight Line Segment) endpoint dan menggunakan pecahan Augmented Farey sequence. DSS endpoint ini dijadikan sebagai titik fitur atau feature point untuk menemukan shape context dari citra. DSS endpoint tersebut digunakan sebagai acuan bounding box yang akan digunakan sebagai object boundary yang dimana setiap sudutnya merupakan reference point. Untuk melakukan Binning Farey Rank, Augmented Farey Table (AFT) harus dibentuk terlebih dahulu berdasarkan Augmented Farey Sequence yang merupakan pengembangan dari Farey Sequence. Farey Sequence hanya meliputi pecahan dengan pembilang dan penyebut yang positif, sedangkan Augmented Farey Sequence meliputi pecahan dengan pembilang dan penyebut positif serta negatif. Pada penelitian ini digunakan 500 data iklan di pinggir jalan yang melengkung, dimana $70 \%$ digunakan sebagai data sample. Dari $\mathbf{7 0 \%}$ data sample tersebut didapatkan ribuan karakter berupa huruf dan angka yang dijadikan data sample. Berdasarkan hasil uji coba penelitian yang dilakukan pada 500 Gambar dimana $30 \%$ sebagai data testing, maka hasil Farey Shape Context untuk mengenali tulisan berupa huruf dan angka pada iklan pinggir jalan yang melengkung mencapai akurasi benar $\mathbf{7 4 . 9 4 \%}$ dan salah $25.06 \%$.
\end{abstract}

Kata Kunci-Augmented Farey Sequence, Farey Table, Object Recognition, Shape Context, Shape Matching.

\section{PENDAhUluan}

$\mathrm{B}$ erkembangnya teknologi yang ada pada dunia menyebabkan berkembangnya dunia IT. Salah satu pengembangan yang berhubungan dengan Gambar / Image yang berupa karakter huruf atau angka. Data gambar berupa karakter huruf atau angka ini harus mampu diproses dan diolah sehingga sistem dapat mengenali huruf / angka tersebut. Dari captcha, hingga iklan - iklan yang ada di pinggir jalan kota Surabaya.

Endang Setyati, Departemen Informatika, Institut Sains dan Teknologi Terpadu Surabaya, Surabaya, Jawa Timur, Indonesia (e-mail: endang@stts.edu)

Raymond Sugiarto, Departemen Informatika, Institut Sains dan Teknologi Terpadu Surabaya, Surabaya, Jawa Timur, Indonesia (e-mail: raymondsugiarto@gmail.com)
Dengan menggunakan percobaan beberapa metode pengenalan gambar diharapkan tingkat keberhasilan pengenalan gambar dapat meningkat sehingga lebih akurat. Dengan ada proses pengenalan ini diharapkan dapat membantu membaca iklan yang ada di pinggir jalan yang ditempelkan pada bidang melengkung.

Iklan - iklan melengkung di pinggir jalan ini terdiri dari beberapa karakter yang berupa huruf dan angka yang akan lebih sulit terbaca dari satu sisi. Selain itu iklan tersebut juga terdiri dari banyak macam background dan bentuk tulisan serta berbagai warna tulisan.

Proses pengenalan tulisan pada iklan - iklan pinggir jalan ini menggunakan metode algoritma pada Image Processing yaitu Shape Context. Metode ini dikenal sebagai metode yang dapat digunakan untuk mengenali suatu bentuk yang telah diubah ubah. Bentuk yang telah diubah - ubah ini akan diterapkan pada iklan - iklan yang melengkung di pinggir jalan. Iklan tersebut difoto kemudian akan dilakukan percobaan pada sistem agar sistem dapat membaca tulisan pada foto tersebut. Dengan bantuan preprocessing pada algoritma Image Processing seperti grayscale, remove background dan sebagainya, akan membantu sistem untuk memperjelas foto / gambar iklan yang melengkung agar Shape Context dapat bekerja lebih maksimal untuk mengenali tulisan pada iklan yang melengkung tersebut.

\section{TINJAUAN PUSTAKA}

Penelitian yang ditulis oleh Sanjoy Pratihar, Najima Begum (2016, Computer Science and Engineering Department) [1] ini mengusulkan pengenalan karakter tulisan tangan dengan menggunakan metode Shape Context. Bentuk adalah atribut visual yang penting dalam gambar. Pencocokan bentuk banyak digunakan dalam Computer Vision seperti pelacakan objek, pengambilan gambar, pendaftaran gambar, pengenalan karakter optik dan lain lain. Penelitian ini telah menyajikan teknik pembahaman Shape Context dengan mudah dan efisien dalam kaitannya dengan urutan Farey dan pecahan Farey.

Pada tahap pre-processing, segmen garis lurus (DDS) yang menentukan batas bentuk yang diekstrasi dengan menggunakan algoritma yang diberikan. Titik akhir dari segmen garis lurus digital yang menentukan batas objek diekstrasi. Prewiit tepi telah digunakan untuk menguji apakah piksel adalah piksel tepi atau tidak. Empat simpul dari persegi panjang area minimum yang meloncat dari titik - titik yang diekstrasi ini digunakan sebagai titik acuan untuk analisis Shape Context. Vektor dari 
empat titik acuan mewakili pecahan urutan Farey yang diperbesar ( $\mathrm{F} \mathrm{n}$ ), yang mencakup ruang 360o penuh (masingmasing titik referensi mencakup satu kuadran).

Lekuk dari titik akhir yang diekstrak yang berkenaan dengan titik referensi dipresentasikan dengan peringkat pecahan yang sesuai dengan urutan Farey. Dari distribusi peringkat Farey, diperoleh histogram yang memberikan objek Shape Context.

Setelah realisasi histogram normal yang sesuai dengan bentuk, digunakan metrik pengukuran jarak Chi-square untuk pelaporan kesamaan. Jarak Chi-square (CSD) dari dua histogram h1 dan h2 diberikan di sini di Persamaan berikut

$$
\operatorname{dist}\left(h_{1}, h_{2}\right)=\frac{1}{2} \sum_{i=0}^{n_{b}^{-1}} \frac{\left(h_{1}[i]-h_{2}[i]\right)^{2}}{\left(h_{1}[i]+h_{2}[i]\right)}
$$

Selanjutnya, untuk menggabungkan invarian rotasi dalam pengukuran kemiripan, digunakan pengukuran jarak jauh Chisquare (SCSD) geser seperti yang diberikan di Persamaan berikut, di mana jumlah geser ditentukan oleh $\mathrm{j}$ dan $0 \leq \mathrm{j} \leq \mathrm{nb}$ 1 .

$$
\operatorname{dist}(h 1, h 2)=\frac{1}{2} \operatorname{Min}\left[\sum_{\forall i, \forall_{j}} \frac{\left(h_{1}[i]-h_{2}\left[(i+j) \bmod n_{b}\right]\right)^{2}}{\left(h_{1}[i]+h_{2}\left[(i+j) \bmod n_{b}\right]\right)}\right]
$$

Penelitian ini telah menunjukkan bagaimana titik akhir yang diekstraksi dari segmen garis lurus digital dapat digunakan secara efisien untuk menemukan konteks bentuk. Untuk melakukannya, telah menggunakan jajaran pecahan Farey yang sesuai dengan vektor arah untuk penemuan binning dan pencocokan yang kuat. Selanjutnya, menunjukkan bagaimana pendekatan ini dapat digunakan untuk analisis konteks bentuk bentuk karakter yang ditarik tangan. Ada ruang lingkup perpanjangan kerja lebih jauh ke arah pencocokan berbasis bentuk dan pengenalan karakter yang ditarik tangan.

Penelitian [2] mengusulkan penggabungan Shape Context dengan algoritma genetika kuantum (QGA) untuk menentukan metode pencocokan dan pengambilan bentuk baru. Metode pencocokan didasarkan pada penemuan korespondensi terbaik antara dua titik set. Metode yang diusulkan menggunakan QGA untuk meneemukan konfigurasi sampel poin terbaik untuk mencapai pencocokan terbaik antara dua bentuk.

Pencocokan bentuk didasarkan pada pengukuran kesamaan antara dua deskriptor bentuk, banyak bentuk representasi dan ukuran kemiripan bentuk dapat ditemukan dalam literatur. Bentuk deskriptor dapat dikelompokkan menjadi tiga kategori: metode berbasis kontur, berbasis wilayah dan titik set.

Metode berbasis kontur hanya menggunakan informasi bentuk kontur, yang menghadap bentuk informasi interior. Deskriptor berbasis wilayah memanfaatkan semua piksel bentuknya. Deskriptor momen, matriks lambung dan bentuk konveks adalah contoh metode berbasis wilayah. Teknik berbasis set point dapat didefinisikan sebagai seperangkat titik sampel yang diambil dari bentuk kontur. Bentuk konteks, skema pemungutan suara adalah metode yang paling populer dalam kategori ini. Dalam kebanyakan kasus poin dipilih secara acak dan memesan poin biasanya tidak diperlukan. Teknik ini didasarkan pada gagasan untuk menemukan korespondensi terbaik antara titik pada dua bentuk.

Pada penelitian ini, algoritma konteks bentuk kuantum diusulkan. Tujuan utama dari pekerjaan ini adalah untuk meningkatkan ketahanan dan kekuatan diskriminatif bentuk pencocokan dan pengambilan dengan menggunakan deskriptor konteks bentuk. Pendekatan QSC yang kami ajukan bermanfaat dari kekuatan algoritma genetika kuantum, yang hadir dalam bentuk superposisi kuantum, di mana setiap individu dapat mewakili tidak hanya satu solusi namun semua kemungkinan solusi untuk masalah tersebut. Pendekatan QSC mencakup semua konfigurasi titik sampel yang mungkin terjadi di ruang pencarian, dan juga menggunakan QGA untuk menemukan orientasi optimal memastikan hasil pencocokan bentuk yang lebih baik untuk bentuk yang diputar dan dibalik.

Penelitian [3] menggunakan deskriptor Shape Context pada jarak pengelompokkan yang tidak merata dan deskripsi bentuk fitur yang lebih luas, deskriptor ini memiliki target titik kontur yang mengatur inversi deformasi. Namun kode verifikasi yang membelit dan melekat memiliki banyak noise yang lebih serius, berbentuk yang sangat jelek, untuk mengatasi keterbatasan deskriptor diatas, maka meningkatkan algoritma baru berdasarkan bentuk relatif, titik pola yang cocok untuk mengidentifikasi kode.

CAPTCHA digunakan untuk membedakan perilaku manusia dan perilaku komputer otomatis, untuk mencegah registrasi dan cracking yang membahayakan. Manual Entry, dimana perlu memasukkan data satu per satu, sangat lambat dibandingkan dengan komputer dan hampir tidak berefek pada server. Latar belakang dan teknik pengenalan kode validasi didasarkan pada teknik pengenalan pola dan pengenalan gambar. Sebelum proses pengenalan gambar, dimana ada teknologi prapengolahan gambar mencakup gambar abu-abu, binerisasi, denoising, koreksi kemiringan, segmentasi karakter. Proses pengindeksan kode awal pre-processing. Teknologi pencocokan pola telah banyak diterapkan di bidang pengenalan karakter, pengenalan wajah, pengambilan gambar berbasis konten, dan pengawasan video cerdas. Ini adalah masalah mendasar untuk pemrosesan gambar dan pengenalan pola komputer.

Pencocokan pola didasarkan pada metode pengukuran berukuran mirip dengan bentuknya. Ada banyak metode pencocokan bentuk sesuai dengan metode klasifikasi yang berbeda, misalnya, sesuai kemampuannya dalam menghadapi titik transformasi menjadi terbagi sebagai berikut: pertama, dengan mencari invariant berbagai perubahan untuk menangani muatan bentuk, invarian ini adalah: Imitasi ditembak invarian, invariants serupa, invarian perspektif. Kedua, dengan menemukan fitur lokal antara target dan sampel untuk mendapatkan toleransi minimum yang sesuai untuk menangani deformasi yang lebih kompleks. Bila menggunakan bentuk atau pencocokan berbasis kontur dibagi antara dua jenis pendekatan berbasis struktur regional atau global ini. Proses pencocokan sampel dasar, tahap ekstraksi fitur dari proses diwakili oleh sebuah proses, tahap identifikasi pencocokan adalah salah satu proses identifikasi, dan estimasi parameter transformasi spasial 


\section{JOURNAL OF INTELLIGENT SYSTEMS AND COMPUTATION}

dan pelatihan iteratif adalah proses pembelajaran.

\section{SHAPE CONTEXT}

Shape Context [4]-[9] adalah sebuah fitur deskriptor yang digunakan untuk pengenalan objek. Shape Context merupakan suatu cara yang memungkinkan untuk mengukur kesamaan bentuk. Shape Context menggambarkan suatu bentuk dengan memperhatikan titik di dalam atau pada batas bentuk itu.

$$
h_{i}(k)=\#\left\{Q \neq P_{i}:\left(Q-P_{i}\right) \in \operatorname{bin}(k)\right\}
$$

Persamaan diatas mendefinisikan Shape Context dari pi. Bin biasanya diambil dari sepasang ruang log-polar. Pada Gambar 3.2, ditunjukkan dimana terdapat perbedaan Shape Context antara dua versi huruf "A" yang berbeda.

Pada gambar 3.2 (a) dan (b) merupakan contoh gambar titik tepi untuk 2 bentuk yang berbeda. Pada gambar 3.2 (c) merupakan diagram bin log-polar yang digunakan untuk menghitung Shape Context. Pada gambar 3.2 (d) merupakan titik poin Shape Context yang ditandai dengan lingkaran pada gambar 3.2 (a). Pada gambar 3.2 (e) adalah titik poin Shape Context yang ditandai dengan diamond pada gambar 3.2 (b). Gambar 3.2 (f) merupakan titik poin Shape Context yang ditandai dengan segitiga. Shape Matching merupakan proses pencocokan objek dengan objek lain berdasarkan tingkat kemiripan bentuk dari objek tersebut.

Sistem yang menggunakan Shape Context untuk Shape Matching terdiri dari beberapa tahap antara lain

1. Secara acak pilih satu set poin yang berada ada tepi bentuk yang diketahui dan satu set poin lain pada tepi bentuk yang tidak diketahui.

2. Hitung Shape Context dari setiap poin pada proses pertama.

3. Cocokan setiap titik dari bentuk yang diketahui ke titik dari bentuk yang tidak diketahui.

4. Hitung "shape distance" antara setiap pasangan titik pada dua bentuk. Gunakan penjumlahan jarak dari Shape Context, jarak tampilan gambar dan energi lentur.

5. Untuk mengidentifikasi bentuk yang tidak diketahui, gunakan klasifikasi nearest-neighbor untuk membandingkan shape distance bentuk yang tidak diketahui dengan shape distance dengan bentuk yang diketahui



(a)|

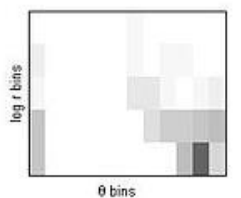

(d)

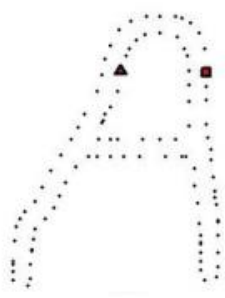

(b)

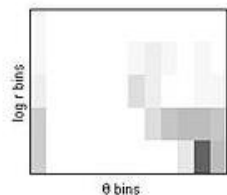

(e)

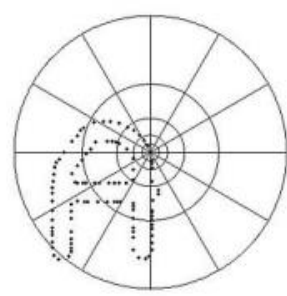

(c)

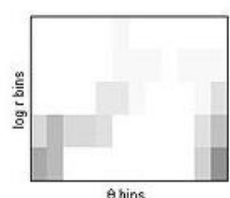

(f)
Gambar 3.1 Perbedaan Shape Context pada huruf A versi berbeda

\section{FAREY SHAPE CONTEXT}

Pada Gambar 3.2 merupakan detil alur sistem yang menjelaskan proses untuk mendapatkan fitur Farey shape context untuk mendeteksi multiple object pada iklan di pinggir jalan yang melengkung sehingga didapatkan object setiap karakter tulisan berupa huruf atau angka untuk dilakukan proses selanjutnya yaitu pengenalan tulisan huruf atau angka.

Citra yang akan diproses dipilih terlebih dahulu. Inputan citra digunakan sebagai sumber utama untuk mendapatkan fitur shape context. Selanjutnya inputan citra diubah dalam level grayscale yaitu gambar hitam putih agar proses berikutnya dapat dilakukan dengan lebih mudah. Citra hasil Grayscale kemudian dilakukan proses deteksi tepi menggunakan Canny [10]. Algoritma Canny ini merupakan salah satu algoritma yang cukup populer dalam penggunaan pengolahan citra khususnya untuk mendeteksi tepi objek pada citra.

Citra hasil deteksi tepi menggunakan Canny tersebut diproses Square Dilation, dimana tepi-tepi pada objek-objek yang ada pada citra dilakukan penebalan tepi agar lebih mudah diproses pada tahap selanjutnya. Penebalan tepi ini juga dilakukan agar objek-objek pada citra dapat terdeteksi pada tahap selanjutnya, selain itu agar objek yang berukuran kecil juga tidak hilang dan dapat dikenali pada proses selanjutnya. Kemudian citra hasil Square Dilation dilakukan proses Fill Holes, dimana setiap objek yang ada pada citra hasil Square Dilation yang hanya terlihat tepi saja, akan diisi sehingga lebih terlihat sebagai kesatuan objek. Fill Holes ini dilakukan agar objek yang berlubang tersebut tidak dianggap sebagai 2 objek yang berbeda pada tahap selanjutnya. 


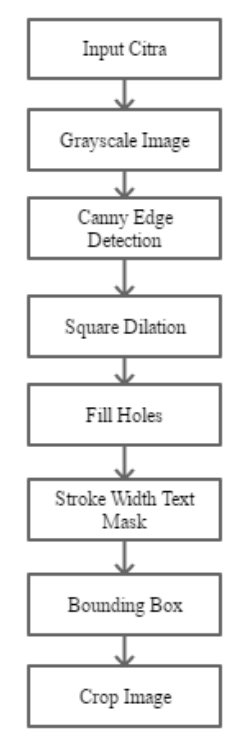

Gambar 3.2 Alur Sistem Deteksi Multiple Object

Citra hasil Fill Holes dilakukan proses Stroke Width Text Mask dengan tujuan untuk menghilangkan objek-objek yang bukan merupakan text yaitu huruf atau angka. Selanjutnya dilakukan proses Bounding Box, dimana setiap objek yang ada pada citra hasil Stroke Width Text Mask dibounding box untuk kemudian akan dilakukan pemotongan citra.

Lalu, citra yang telah di Bounding Box dilakukan proses Crop Image atau pemotongan citra. Pemotongan Citra ini dilakukan untuk mendapatkan citra dari setiap objek secara terpisah untuk melakukan proses pengenalan karakter setiap objek.
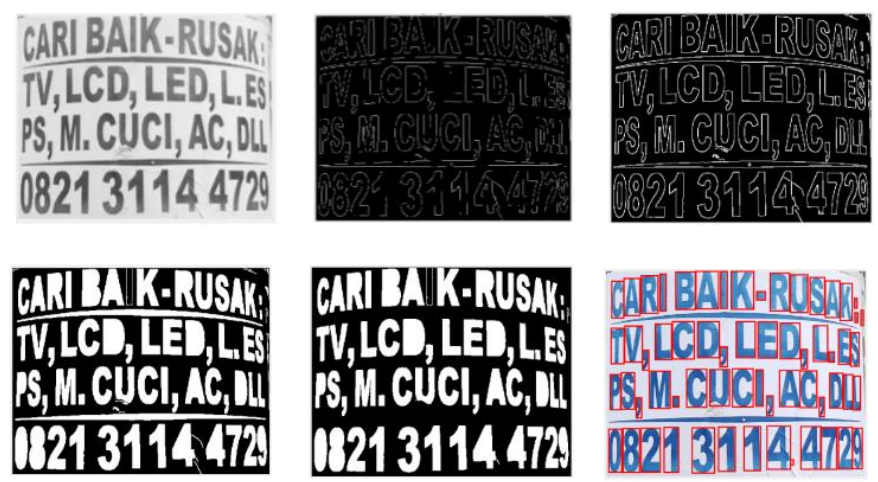

Gambar 3.3 Alur Sistem Farey Shape Context

Citra yang akan diproses dipilih terlebih dahulu. Selanjutnya akan diproses Farey Shape Context per single object, seperti alur Farey Shape Context pada gambar 3.4. Input citra digunakan sebagai sumber utama untuk mendapatkan fitur shape context. Input citra diubah dalam level grayscale agar proses berikutnya dapat dilakukan dengan lebih mudah.

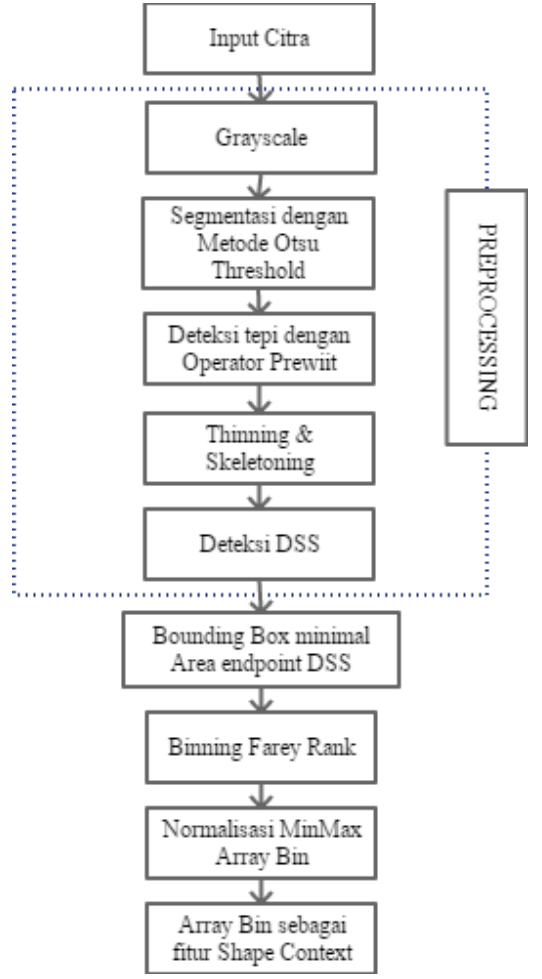

Gambar 3.4 Alur Sistem Farey Shape Context

Citra yang sudah digrayscale kemudian dilakukan proses segmentasi untuk memisahkan antara objek dengan latar belakang. Segmentasi menggunakan metode Otsu. Citra yang sudah disegmentasi kemudian dilakukan proses deteksi tepi dengan menggunakan operator Prewit sehingga didapatkan tepi-tepi dari objek citra yang kemudian digunakan untuk menemukan DSS (Digital Straight Line Segment). Deteksi tepi yang sudah didapatkan kemudian digunakan sebagai dasar untuk melakukan proses penipisan menggunakan metode Thinning dan Skeletoning. Deteksi tepi yang sudah didapatkan kemudian digunakan sebagai acuan untuk menemukan Digital Straight Line Segment dari citra. Garis lurus yang terdapat dalam citra akan dideteksi dalam tahap ini dengan tujuan agar endpoint dari DSS tersebut dijadikan sebagai titik fitur atau feature point untuk menemukan shape context dari citra.

Berikut ini adalah hasil yang didapatkan setelah dilakukan proses deteksi DSS.

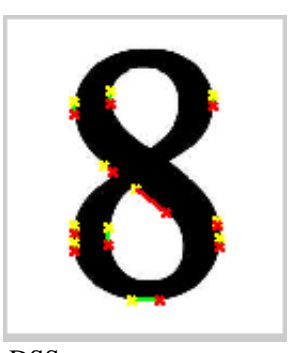

Gambar 3.5 Citra Hasil DSS

Pada gambar 3.5 merupakan hasil deteksi DSS dengan menggunakan metode Hough Transform. Hough Transform digunakan untuk mencari Hough Peaks. Hough Peaks 
merupakan puncak dari transformasi Hough yang ditandai dengan kotak warna hijau pada grafik pada Gambar 3.6. Hough Peaks terdiri dari sumbu X dan Y yang mewakili rho dan theta, dimana rho merupakan resolusi jarak dari akumulator dengan satuan pixel dan theta merupakan resolusi sudut akumulator dengan satuan radian
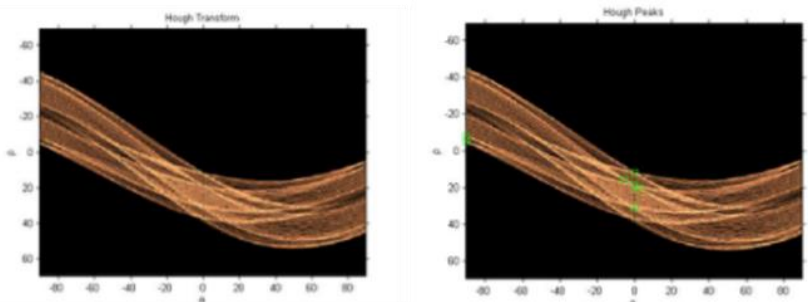

Gambar 3.6 Hough Transform dan Hough Peaks

Garis lurus pada citra ditunjukkan dengan warna hijau sedangkan titik awal (startpoint) dan titik akhir (endpoint) masing-masing berwarna kuning dan merah. Total terdapat 11 garis lurus dengan 11 startpoint dan 11 endpoint yang didapatkan. Dalam kasus ini, yang diutamakan untuk digunakan sebagai feature point adalah endpoint dari DSS yang didapatkan. DSS endpoint yang didapatkan pada proses sebelumnya digunakan sebagai acuan untuk menemukan bounding box. Bounding box didapatkan berdasarkan minimum area dari endpoint yang didapatkan. Bounding box tersebut digunakan sebagai object boundary yang dimana setiap sudutnya merupakan reference point yang merupakan vektor menuju pada feature point yang didapatkan. Berikut ini adalah hasil bounding box endpoint yang didapatkan.

Pada gambar 3.7 merupakan hasil bounding box endpoint yang digunakan untuk menunjukkan shape context dari object. Dari gambar tersebut didapatkan reference point terdapat 4 titik dan feature point terdapat 11 titik. Sehingga vektor dari setiap reference point dan setiap feature point merepresentasikan pecahan dari Augmented Farey Sequence yang mencakup ruang $360^{\circ}$ (setiap reference point mencakup 1 kuadran).

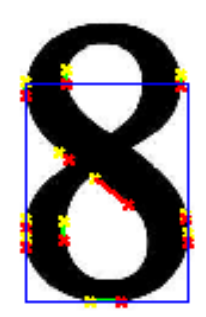

Gambar 3.7 Citra Hasil Bouding Box End Point

Untuk melakukan Binning Farey Rank, pertama-tama yang harus dilakukan adalah membentuk Augmented Farey Table (AFT). AFT dibentuk berdasarkan Augmented Farey Sequence yang merupakan pengembangan dari Farey Sequence. Beda Farey Sequence dan Augnented Farey Sequence adalah nilai pecahannya. Farey Sequence hanya meliputi pecahan dengan pembilang dan penyebut yang positif sedangkan Augmented Farey Sequence meliputi pecahan dengan pembilang dan penyebut positif serta negatif. Pada penelitian ini, AFT dibentuk dengan order 100 yang berarti pembilang dan penyebut akan bernilai $-100 \geq n \leq 100$.

Setelah didapatkan AFT maka proses selanjutnya adalah melakukan Binning Farey Rank. Proses pembentukan AFT bersifat independent artinya adalah tidak harus dilakukan bersamaan dengan proses binning tetapi harus dilakukan terlebih dahulu sebelum melakukan binning. Berikut ini adalah algoritma 1 yang digunakan untuk melakukan proses Binning Farey Rank.



Pada paper ini jumlah bin yang digunakan adalah 32 untuk masing-masing objek yang diberikan. Sehingga array bin akan berjumlah 32. Array bin yang berjumlah 32 tersebut akan dibatasi dengan sejumlah interval untuk setiap binnya. Batasan interval berhubungan dengan nilai pecahan Augmented Farey yang didapatkan. Batasan interval tersebut juga memberikan pengaruh terhadap penambahan bobot pada setiap bin. Berikut ini adalah hasil array bin yang didapatkan setelah dilakukan proses binning. 


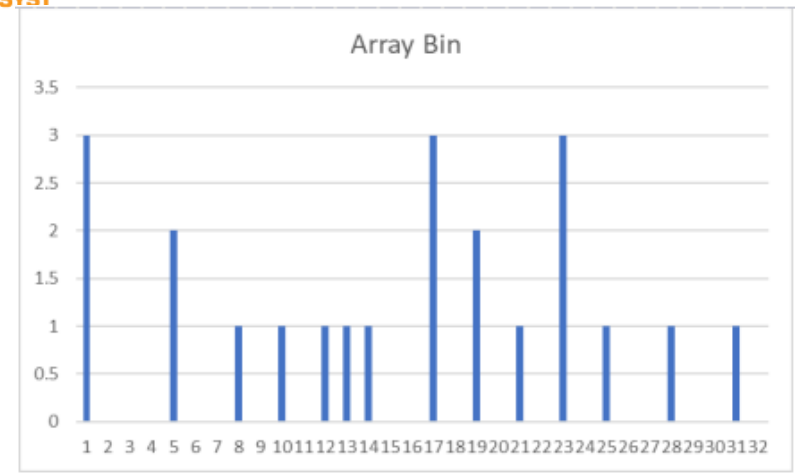

Gambar 3.7 Array Bin

Pada gambar 3.7 merupakan hasil array bin yang didapatkan setelah proses binning. Array yang didapatkan berjumlah 32 dengan nilai integer positif yang bervariasi. Setelah didapatkan array bin, proses selanjutnya adalah melakukan normalisasi dengan metode MinMax, agar memiliki bobot yang relevan dalam menunjukkan shape context dari object.

Pada kasus yang sebenarnya dalam pendeteksian text diketahui bahwa dapat terjadi object yang lebih dari satu dalam sebuah inputan citra. Jika object lebih dari satu maka sebelum melakukan perhitungan shape context, maka dilakukan proses deteksi multiple object terlebih dahulu.

\section{HASIL EKSPERIMEN DAN PENELITIAN}

Pada bab ini akan dijelaskan hasil uji coba penelitian yang telah dilakukan pada beberapa gambar. Object Shape Context pada salah satu karakter angka 8, seperti pada Gambar 4.1, yang tertera pada salah satu data testing yang ada.

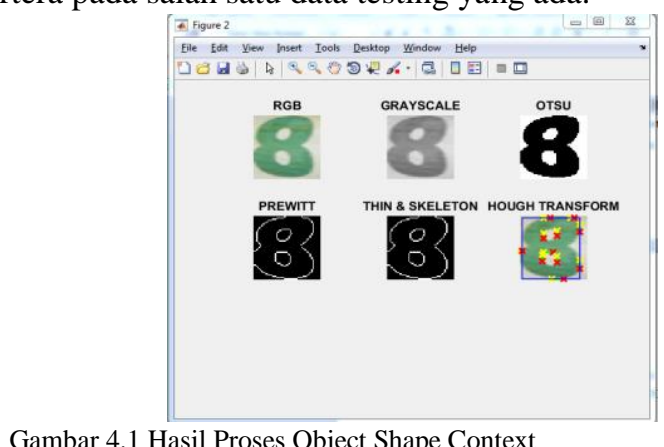

Angka tersebut diproses dengan RGB, grayscale, Otsu, Prewitt dan Thin \& Skeleton hingga Hough Transform untuk mendapatkan startpoint dan endpoint angka tersebut.

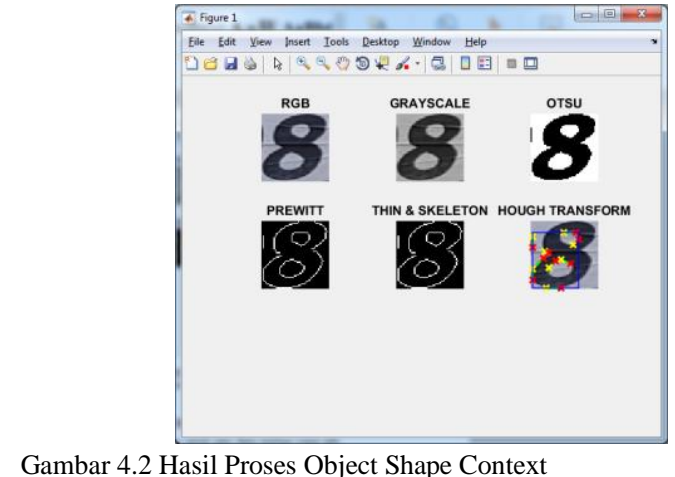

Jika dibandingkan dengan Gambar 4.2, karakter angka tersebut sama yaitu 8 , akan tetapi angka 8 pada Gambar 4.2 terlihat lebih miring ke kanan. Keduanya diproses dengan metode yang sama, akan tetapi hasil Hough Transform nya berbeda karena pada Gambar 4.2 terlihat lebih miring ke kanan sehingga startpoint dan endpointnya berbeda.

Pada penelitian ini digunakan 500 data iklan di pinggir jalan yang melengkung, dimana $70 \%$ digunakan sebagai data sampel. Dari $70 \%$ data training tersebut didapatkan ribuan karakter berupa huruf dan angka yang dijadikan data sample, seperti contoh data sample Angka 0 pada Gambar 4.3.



Setelah selesai proses training, maka akan dilakukan uji coba dengan meletakkan gambar pada direktori tertentu. Dengan dilakukan metode Grayscale, Canny Edge Detection, Square Dilation, Fill Holes, Stroke Width Text Mask, maka didapatkan pengenalan tulisan pada iklan pinggir jalan yang melengkung seperti pada Gambar 4.4

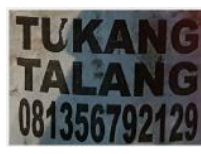

(a)

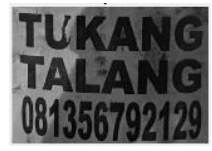

(b)

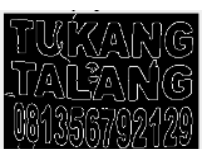

(c)

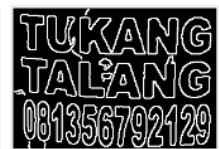

(d)



(e) (f)

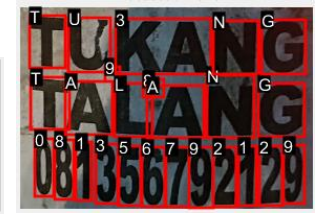

(g)
Gambar 4.4 Proses Pengenalan Tulisan. (a) Gambar Asli, (b) Grayscale, (c) Canny Edge Detection, (d) Square Dilation, (e) Fill Holes, (f) Stroke Width Text Mask, (g) Detected Text 


\section{JOURNAL OF INTELLIGENT SYSTEMS AND COMPUTATION}

Dari contoh tersebut terlihat 12 huruf, 12 angka, sehingga total tulisan 24. Program berhasil mengenali 10 huruf, 12 angka, sehingga total tulisan yang dikenali yaitu 22. Tingkat akurasi Gambar 5.12 yaitu $91.66 \%$.

Berdasarkan hasil uji coba penelitian yang dilakukan pada 500 Gambar dimana 30\% sebagai data testing, maka hasil Farey Shape Context untuk mengenali tulisan berupa huruf dan angka pada iklan pinggir jalan yang melengkung mencapai akurasi benar $74.94 \%$ dan salah $25.06 \%$.

\section{KESIMPULAN}

Pada paper ini, telah ditunjukkan algoritma Farey Shape Context untuk mengenali tulisan pada iklan pinggir jalan yang melengkung. Berdasarkan hasil penelitian ini, penulis mengambil kesimpulan dari penelitian pengenalan tulisan pada iklan pinggir jalan yang melengkung, yaitu dari 500 data yang digunakan, dimana 30\% data digunakan sebagai data testing, maka Pengenalan tulisan berupa huruf dan angka menggunakan Farey Shape Context dapat mencapai hasil akurasi kebenaran hingga $74.94 \%$.

Dari hasil penelitian ini, penulis juga memberikan saran untuk penelitian selanjutnya bahwa Fitur Farey bergantung pada DSS endpoint, sehingga jika tidak ditemukan secara akurat dapat merusak hasil prediksi, maka disarankan untuk menambahkan fitur lain selain DSS endpoint yang mendukung DSS endpoint untuk dapat meningkatkan akurasi hasil prediksi.

Selain itu juga Fitur Farey menggunakan pecahan Augmented Farey Sequence maka jika terdapat sebuah kasus dimana pembilang dan penyebut lebih besar dari order $n$ maka untuk mencari pecahan terdekat bisa jadi tidak ditemukan dan memberikan efek pada prediksi. Oleh karena itu, disarankan untuk menambahkan metode pencarian pecahan terdekat yang lebih baik sehingga meningkatkan akurasi prediksi.

\section{DAFTAR PUSTAKA}

S. Pratihar and N. Begum, "Understanding shape context by analysis of Farey ranks," in 2016 5th International Conference on Informatics, Electronics and Vision (ICIEV), 2016, pp. 580-585.

[2] K. M. Mezghiche, K. E. Melkemi, and S. Foufou, "Matching with quantum genetic algorithm and shape contexts," in 2014 IEEE/ACS 11th International Conference on Computer Systems and Applications (AICCSA), 2014, pp. 536-542.

[3] G. An and W. Yu, "Captcha recognition algorithm based on the relative shape context and point pattern matching," in 2017 9th International Conference on Measuring Technology and Mechatronics Automation (ICMTMA), 2017, pp. 168-172.

[4] N. Bhuptani and B. Talati, "Variations in Shape Context Descriptor: A survey," Int. J. Comput. Appl., vol. 975, p. 8887, 2014.

[5] Y.-P. Lin and K.-W. Hsu, "Using Color Difference with Shape Context for Logo Recognition.," J. Softw., vol. 9, no. 8, pp. 21882193, 2014.

[6] S. Belongie, J. Malik, and J. Puzicha, "Shape context: A new descriptor for shape matching and object recognition," Adv. Neural Inf. Process. Syst., vol. 13, 2000.

[7] A. Thayananthan, B. Stenger, P. H. S. Torr, and R. Cipolla, "Shape context and chamfer matching in cluttered scenes," in 2003 IEEE Computer Society Conference on Computer Vision and Pattern Recognition, 2003. Proceedings., 2003, vol. 1, pp. I--I.

[8] J. Qi, L. Wenhui, L. Yi, and Y. YingTao, "An Efficient Object Recognition Method Based On Pyramid Match Kernel Using Shape Contexts," in 2008 IEEE International Symposium on Knowledge Acquisition and Modeling Workshop, 2008, pp. 18-21.
S. G. Salve and K. C. Jondhale, "Shape matching and object recognition using shape contexts," in 2010 3rd International Conference on Computer Science and Information Technology, 2010, vol. 9, pp. 471-474.

[10] J. Canny, "A computational approach to edge detection," IEEE Trans. Pattern Anal. Mach. Intell., no. 6, pp. 679-698, 1986. 